\title{
FREEDOM OF CONSCIENCE AND COVID-19 VACCINATION: RECONCILING CONTRADICTORY FORCES
}

\section{Lóránt CSINK ${ }^{1}$}

Compulsory COVID vaccination is a timely question to ask as more and more countries introduce it. There is a growing body of case law and literature on child vaccination against a number of well-known diseases, ${ }^{2}$ yet the current issue involving the compulsory vaccination of adults against COVID-19 presents a new case. I hypothesise as follows: (a) compulsory vaccination is constitutional, under certain conditions; (b) alternative behaviour must be tolerated if it produces the same end. I verify these hypotheses by analysing the role of conscience in vaccinations in general and in COVID-19 vaccination in particular. I consider the Hungarian context, but the conclusions might apply to other countries as well. The key issue is the extent to which the government should respect individual conscience during a pandemic. I first discuss what conscience is in legal terms. Second, I discuss the legal nature and background of COVID-19 vaccination. Third, I describe the decision of the Hungarian Constitutional Court on mandatory vaccination and compare the current situation with the previous one. Fourth, I analyse the outcome of the 'comparative test of burdens'. Finally, I summarise my conclusions.

\begin{tabular}{l|l} 
freedom of conscience \\
COVID-19 \\
vaccination \\
compulsory vaccination \\
contradictory forces
\end{tabular}

\section{To begin with}

If you travel through port towns of the North Sea, the first thing that may surprise you is the large number of churches, irrespective of the town's population. The reason why there are so many churches might be even more surprising: People say that sailors who lived through dangerous events at sea promised that they would give donations and

1 | Professor, Faculty of Law, Pázmány Péter Catholic University in Budapest, Hungary, csink. lorant@jak.ppke.hu.

2 | The constitutional perspective on child vaccination is summarised by Szendrői, 2020, pp. 186-199.

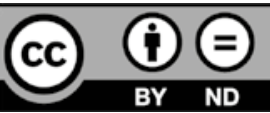


build statues or even churches if they survived. Many of them were honest enough to keep their promises when they returned, resulting in many churches, although the number of churchgoers remained the same. Centuries later, one may conclude that there is no use for so many churches, or at least that it is irrational to build them.

Rationality does not always support conscience. It often does: Being true to one's conscience is rational. However, conscience sometimes overrules rationality and leads to behaviour that does not make logical sense, at least to others.

How can we evaluate conscience in legal terms? Freedom of conscience is accepted if it is rational and when it remains the generally accepted framework for rules. However, what if freedom of conscience were illogical and illegal?

\section{On conscience}

Freedom of conscience is clearly protected in constitutional terms. It is closely connected to human dignity: only human beings have a conscience. In other words, only human beings can act according to or against their conscience. Machines have no dignity and do not have a conscience. If they function well, they always do what they are programmed to do. They have no conscience that could overrule their 'rationality'.

Consequently, human beings have the fundamental right to not be rational, to obey their conscience even if it does not make logical sense. On the other hand, science is personal. In many cases, it cannot be explained in logical terms, as it is beyond rationality.

Freedom of conscience is often considered part of freedom of religion. Torfs differentiates between three layers of freedom of religion. The first layer is that of individual religious freedom: Everybody has the right to adhere to any religious conviction or belief, including the right to change one's religion or to not be religious at all. The second layer is collective religious freedom, which implies freedom of community building and the freedom to organise public manifestations of faith. The third layer is institutional religious freedom, implying people's right to organise themselves structurally into religious groups and associations, or into communities and churches with internal norms that create a subculture. ${ }^{3}$

In Hungary's Fundamental Law, the situation is slightly different: Freedom of conscience is a separate right; it is not part of freedom of religion, but is closely connected to it. Article VII of the Fundamental Law stipulates the following:

Everyone shall have the right to freedom of thought, conscience and religion. This right shall include the freedom to choose or change one's religion or other beliefs, and the freedom of everyone to manifest, abstain from manifesting, practice or teach his or her religion or other belief through religious acts, rites, or otherwise, either individually or jointly with others, either in public or in private life.

Conscience is not necessarily religious; it covers all views, ideologies, and convictions. The content of conviction is irrelevant to the law. Accepting the view of a historical 
church is part of freedom of conscience, as is the acceptance of any other belief or the lack thereof.

Many argue that freedom of conscience exists only within the framework of law thus, that conscience cannot be grounds for exemptions under the law. ${ }^{4}$ In general, I find such statements dangerous. Freedom of conscience is a constitutional right. If laws are automatic restrictions of constitutional rights, it means that the content of a constitutional right is what the law allows it to be. There is therefore no need for a constitution because it is the law that determines what our rights are, not the constitution. My understanding is the exact opposite: Laws should adhere to the content of the constitution.

Why respect other people's consciousness? On the one hand, laws serve the common good - at least, that is what we choose to believe. Political entities make laws to achieve objectives that are socially beneficial. On the other hand, constitutional rights also serve the common good. In our culture, constitutional rights have been essential for preserving the state and society. Furthermore, conscience is not an entirely private matter; it also manifests in social life: 'Historically, religion and morality have been closely related. However, they are different ideas, different realities, and different meta-legal concepts. So they affect secular legal systems in different ways'. ${ }^{5}$ Acting according to one's conscience is a virtue, even if individual conscience differs from person to person. ${ }^{6}$

When laws and constitutional rights conflict, there must be a test for the greater good'. There is no general answer. One cannot say either that laws are always more important than conscience or that matters of conscience should always create exceptions to the general rule. Courts can make decisions only on a case-by-case basis.

Lastly, it is worth mentioning that conscience is always personal. I strongly disagree with the idea that conscience is no more than a product of organised religion. Simply because traditional religions do not oppose vaccination, this does not mean that concerns regarding COVID-19 vaccination cannot be matters of conscience. ${ }^{7}$

\section{Background on vaccination}

The COVID-19 pandemic has left hardly any aspect of day-to-day life unchanged. The pandemic has posed an enormous challenge to healthcare, left ruined economies, and hindered social relations. In these circumstances, there are huge hopes that medical scientists can come up with a solution that will allow us to return to normalcy. This is why optimism began to grow when the arrival of vaccines was announced.

As Harrison and Wu point out, 'vaccine optimism has also been prominent in the public imagination during the early weeks of the COVID-19 epidemic, amidst a mixture

4 | According to a court ruling, public health and the prevention of plagues overrule personal integrity (BH2020.147.). I find that such a general statement oversimplifies the issue.

5 | Domingo, 2015, p. 180.

6| Kuminetz, 2009, p. 20.

7 | In their study, Pelčić and colleagues analyse the views of several religions on vaccination (Pelčić et al., 2016, pp. 516-521). Not to argue with their conclusions, but it is entirely possible for someone (either religious or not) to have a view different from that of religions. Freedom of conscience must be protected even if not supported by religions. 
of bravado, uncertainty and fear.'8 However, vaccine hesitancy is also unsurprising: Some are cautious and prefer to wait until there is more information on the virus and the vaccine. Some objections to vaccinations are based on freedom of conscience, whereby people refuse them on religious grounds or see the pandemic and vaccines as part of a conspiracy.

Unsurprisingly, the question of vaccination soon became a political issue. Governments are rushing to obtain as many vaccines as possible and to vaccinate as many people as possible, while some question whether all vaccines are effective and whether governments' vaccination policies are satisfactory.

Most countries are seeing debates about whether COVID-19 vaccination should be mandatory and, if it remains voluntary, what benefits should be granted to those who are vaccinated. For our purposes, a crucial question is whether conscience can be grounds for an exemption from vaccination.

At first glance, mandatory vaccination is generally accepted. In constitutional terms, the aim of avoiding diseases and reducing their impact seems to provide constitutional grounds for restricting privacy and medical self-determination. When considering previous mandatory vaccinations, one may find that vaccination policies have been heterogeneous across countries: they 'vary not only in the presence or absence of a mandate but also in the implementation and enforcement of the mandates as well as in the consequences faced by individuals who fail to comply with their country's policy.' ${ }^{9}$ Hungary has the world's greatest number of mandatory vaccines and the highest fines for failure to comply with mandatory vaccination. ${ }^{10}$

Mandatory vaccination mainly concerns children, who receive various vaccines. Most legal issues pertain to the question of whether parents have the right to object to their children being vaccinated or to substitute these vaccines with different ones. Hungarian jurisprudence includes cases that hinge on whether a parent's failure to comply with vaccination can be considered as an 'abuse of a minor' (i.e. a criminal offence). Several court decisions express scepticism, stating that a lack of vaccination in itself does not endanger the child's physical and mental health and integrity and therefore cannot be grounds for criminal punishment ${ }^{11}$ However, this judgment is criticised for ignoring the possibility of infection, which means that the child is endangered. ${ }^{12}$

In the United States, mandatory vaccination is generally accepted. The recent COVID-19 situation has shed new light on the century-old Jacobson v. Massachusetts case [197 U.S. 11 (1905)], which concerned the question of whether a state may prescribe mandatory vaccination during a pandemic. The court held that the statute was not invalid for an adult residing in the community and fit to receive the vaccination, as it was not in derogation of any of the rights of such a person under the Fourteenth Amendment. Interestingly, interpretations of the case vary: Certain courts view Jacobson as virtually a blank cheque for government action; others apply standard constitutional doctrines with little consideration given to the emergency issue..$^{13}$ It is worth

8 | Harrison and Wu, 2020, p. 325.

9 | Vaz et al., 2020.

10 | Vaz et al., 2020.

11 | Supreme Court of Hungary, Bfv.II.25/2009/5.

12 | Dávid, 2011, p. 38.

13 | Farber, 2020, p. 834. 
mentioning that all US states grant medical exemptions; 45 states and Washington DC grant religious exemptions, and 15 states also allow philosophical exemptions from vaccination. ${ }^{14}$ Seemingly, courts have long recognised that states are not required to provide religious exemptions to vaccination mandates, although most of them do. ${ }^{15}$

\section{COVID-19 vaccination in Hungary}

As in other European countries, COVID-19 vaccination is not mandatory in Hungary. At first glance, COVID-19 vaccines are similar to seasonal influenza vaccines, which are not obligatory. However, there are two major differences. First, the influenza vaccine is not a social issue, neither on a political level nor in everyday conversation. Politicians do not campaign on influenza vaccines, and people do not argue over being vaccinated against the flu. By contrast, politicians run massive pro-COVID-19 vaccine campaigns, leading to crucial disagreements between vaccine optimists and vaccine hesitants. Unlike with influenza vaccination, questions about COVID-19 vaccination have the potential to break up social groups, communities, and friendships.

Second, vaccination for influenza has no impact on social life. People can go to restaurants and movies and can travel irrespective of whether they are vaccinated. COVID-19 vaccination is very different. The government has issued vaccination cards for those who received the first dose of any among the nationally recognised vaccines (Pfizer-BioNtech, Moderna, Astra Zeneca, Janssen, Sputnik, and Sinopharm) or if they have been infected with COVID-19. In the latter case, the vaccination card expires in six months; otherwise, the card has no expiry date. ${ }^{16}$

For a long time, having a social life was impossible without a vaccination card. Entry to sports facilities, indoor restaurants, hotels, and social events were subject to vaccination status. These have led to semi-mandatory COVID-19 vaccination: The vaccine is officially voluntary but is practically required for social life. The situation changed in June 2021. After the number of vaccinated individuals in Hungary increased to 5.5 million, the government reduced the number of events for which vaccination is required. Many say that this is a turning point; life is getting easier and the vaccination ID has less relevance. However, I am not optimistic. If another COVID-19 wave hits, vaccination ID may become important again. On the other hand, the mere fact that there are fewer places where a vaccination ID is necessary does not mean that there is no need for constitutional evaluation.

In the following, I examine whether legislation can mandate COVID-19 vaccines and whether there are constitutional criteria for vaccination cards.

14 | Gostin, Salmon, and Larson, 2021, p. 532.

15 | Killmond, 2017, p. 913.

16 | This paper does not address the problem that national and EU approvals of vaccines vary; the EU does not acknowledge all vaccines that have national approval (e.g. Sputnik). Therefore, it is entirely possible that someone is vaccinated in Hungary but is not the beneficiary of the full range of vaccines granted approval in other countries. It further complicates the matter that, especially in the early phase of vaccination, people could not decide which vaccine to take. 


\section{Constitutional issues regarding mandatory vaccination}

As mentioned, numerous vaccines are mandatory for children of certain ages. A small number of parents occasionally object to their children being vaccinated, mostly on religious or philosophical grounds.

The most well-known Hungarian case dates back to 1995. The parents in question failed to comply with the vaccination protocol, which led administrative agencies to impose a fine and order the parents to have the child vaccinated. The parents challenged the administrative decision in court, but the court rejected the petition. As pointed out by the court, under the Constitution, everyone has the right to freedom of thought, freedom of conscience, and freedom of religion; however, unless it is otherwise ordered by law, exercising these rights does not create grounds for exemption from the duties of citizens.

The parents challenged the court decision in the Constitutional Court. The court decided on the case in 2007, almost 10 years after the constitutional complaint was filed (when child vaccination was practically out of the question). The decision (39/2007 [VI. 20]) proved to be a landmark decision. The Constitutional Court examined whether people can refuse obligatory vaccination by referring to their freedom of conscience. The Court argued as follows:

In constitutional democracies it is a frequently debated issue whether citizens may be exempt from statutes that prescribe general obligations based on their conscience and their religious beliefs. (...) When considering the proportionality of the restriction of a fundamental right in this type of regulation, the Constitutional Court applies a different, so-called 'comparative test of burdens' for those whose conscience and religious freedoms are also violated by the regulations. On the one hand, one should take into consideration the basic principle of a state under the rule of law which says that everybody has rights and obligations in the same legal system, and therefore the statutes apply to all in such a way that the law treats everybody as equals (as individuals with equal dignity). On the other hand, it should not be ignored that the fundamental values of a constitutional democracy include a diversity of political opinion and also the freedom and autonomy of individuals and their communities. Therefore, it may not be established as a general rule that the freedom of conscience and religion should always be an exception from the laws that apply to all, and likewise, the rule of laws may not be declared fully applicable to the internal life of a religious community.

\section{The Court also considered}

the circumstance that some of those who refuse compulsory vaccination for religious reasons or because of their conscience do not disapprove of vaccinations as a whole; they usually only object to vaccines of a certain composition (quite similarly to condemning blood transfusion). If there are several types of vaccines available, there is an opportunity to provide 'alternative rules of conduct within reasonable limits' by applying vaccines of different compositions.

As a consequence, the law should combine legislative purpose and freedom of conscience, and it should support alternative behaviour that results in the same outcome and is also in accordance with conscience. 
In constitutional terms, the key element is a comparative test of burdens. The first step is examining the connection between conscience and the activity in question: The closer the connection, the more reasonable it is to make an exception to the general rule. Second, it is also necessary to examine the extent to which the activity influences others: The greater the influence, the less reasonable it is to make exceptions. In terms of freedom of religion, the comparative burden test is as follows: The law may legitimately aim to restrict certain religious activities; on the other hand, religion may provide exemptions from general rules under certain conditions. There are two key issues: the extent to which the behaviour is linked to conscience (the more strongly they are linked, the more likely it will result in an exemption) and how it pertains to third parties (the more it influences others, the lower the likelihood that it will result in an exemption). ${ }^{17}$

\section{Comparative test of burdens and COVID-19 vaccination}

It seems to be important to examine how COVID-19 vaccination relates, in a constitutional sense, to child vaccinations - in other words, whether the 39/2007 (VI. 20) decision helps in evaluating the current situation.

One important distinction is that vaccine hesitancy is much less prevalent in cases of child vaccination. No social issue is triggered if only approximately five or six parents annually seek to avoid vaccines. A few exemptions do not risk herd immunity; an epidemic does not result if a few children are not vaccinated. However, if one-third of the population is vaccine-hesitant and is not willing to get vaccinated, herd immunity may be at risk. ${ }^{18}$

Moreover, COVID-19 vaccination is a significant social topic: Most people have a strong (either positive or negative) opinion on vaccination and on those who are not vaccinated. This impact is not only emotional but is also practical. For instance, if vaccination status is a condition of entry to a restaurant and someone in a company of friends does not have a vaccination ID, either the whole company will be excluded from the restaurant or the group will leave the non-vaccinated members behind.

The social relevance of COVID-19 vaccination brings us close to it being mandatory. Many vaccines for children are mandatory, while there are also voluntary vaccinations

17 | The Constitutional Court used the comparative test of burdens twice (the second one was in 2009), and neither occurred under the current constitution (Fundamental Law). Still, I presume the test is still applicable. Decision 3049/2020 (III. 2.) CC had a very similar outcome, without mentioning the test. That decision examined the connection between loud religious activity and the private lives of others. The neighbours of a Muslim individual referred to their privacy when speaking against his loud prayers. In that case, the court of first instance concluded that, although freedom of religion covers prayers and singing, such activities must be balanced with the privacy of others. This latter covers a decent private life and the sanctity of the home. The Constitutional Court accepted the position and stated that the court decision was in accordance with the constitutional provision on freedom of religion. The Court added that it is necessary to balance the competing interests case by case.

18| I do not have reliable data on the rate of vaccine hesitancy in Hungary. Surveys estimate between 16 and $30 \%$ of the population, which is a big difference. By now, anyone who wants a vaccine receives one, and the vaccinated population has increased to 5.5 million. Considering that 8.35 million people in Hungary are above 15 (the age group for whom vaccine availability is highest), 35\% of all people in Hungary above 15 have not received the vaccine. In any case, the COVID-19 vaccination rate is far from providing herd immunity. 
(e.g. varicella, croup). At first glance, one may say that mandatory vaccination does have constitutional criteria, but voluntary vaccination is a mere medical issue, and has nothing to do with fundamental rights. I acknowledge that, in most cases, voluntary vaccination is out of the scope of the constitution. However, if vaccination is a condition for participation in social life, it becomes a legal issue. Therefore, I conclude that COVID-19 vaccination is semi-mandatory in Hungary, as described above. In particular, the sanctions (the consequences of not being vaccinated) are almost as grave as they are in the case of mandatory vaccination. The most basic consequence of not complying with mandatory vaccination is that it may, in special cases, lead to a criminal issue. By contrast, the lack of a COVID-19 vaccine has non-legal but very significant consequences.

One of the most significant differences is that COVID-19 vaccination is based on self-determination, while child vaccination is not. Children cannot decide on their own vaccinations; it is all up to the parents. It is not to underestimate parental rights to say that vaccination concerns the individual more. Therefore, when legislation declares a vaccination to be mandatory, stronger arguments are needed to restrict self-determination. In other words, there are stronger reasons to be exempt if I am deciding on my own body than there are when the decision concerns someone else.

A crucial question might be whether COVID-19 vaccination has an impact on others. In this context, constitutional law must rely on medical science, and medical doctors are obviously very cautious when making statements on the coronavirus and COVID-19 vaccines. The question is whether vaccination reduces only symptoms or reduces the possibility of transmitting the disease.

Finally, it is also important to consider if the regulation allows for alternative behaviour. Child vaccines are generally substitutable. Parents may, at their own expense, replace a vaccine with another that they believe is more suitable. By contrast, a vaccination ID is granted for COVID-19 vaccination or for a documented infection with the virus. However, alternative behaviour is not possible in this case: Negative PCR or antigen tests do not grant a vaccination ID. The main differences are summarised in the chart below.

\begin{tabular}{|l|l|l|}
\hline & $\begin{array}{l}\text { Child vaccination (as decided } \\
\text { by 39/2007 CC) }\end{array}$ & COVID-19 vaccination \\
\hline Social relevance & Little & Great \\
\hline Mandatory nature & Mandatory & Voluntary \\
\hline Consequence & $\begin{array}{l}\text { Mostly administrative } \\
\text { sanctions (fines) }\end{array}$ & Exclusion from social life \\
\hline Self-determination & No & Yes \\
\hline Freedom of conscience & Yes & Yes \\
\hline Effect on others & ??? & ??? \\
\hline Alternative behaviour & Yes & No \\
\hline
\end{tabular}




\section{Testing COVID-19 vaccination on comparative test of burdens}

The comparative test of burdens has two components: First, it tests the extent to which the behaviour required by law is linked to conscience; second, it tests how the behaviour affects others.

As regards the first element, the law faces difficulties. One cannot determine others' conscience; therefore, it is difficult to evaluate the link between behaviour and conscience. ${ }^{19}$ The law can only make educated guesses.

Here, the link with conscience seems strong, as vaccination constitutes a physical intervention in a person's body. It is also important to determine the rationale of the debate over vaccination. People are likely to decide rationally if there is an honest debate based on the medical background, the effects and possible side effects, and the advantages and disadvantages of vaccines. However, if there is a massive campaign that targets emotions and criticises everyone who has a different opinion, then people are more likely to be irrational and emotional, or even turn to conspiracy theories.

The second element of the test is how it relates to others. The key question here is whether vaccination reduces transmission of the virus. If it does, then the impact on third parties is significant: Vaccinated people cannot transmit the virus, which means that the spread of the disease is slower. Contrariwise, if vaccines only diminish the symptoms but do not prevent transmission, vaccination does not affect third parties. Indeed, vaccination seems to have an effect on the individual, as non-vaccinated people are more likely to require medical help, which increases the workload on doctors and the healthcare system. However, many other behaviours that pose a health risk (e.g. smoking, heavy drinking, extreme sports) are legal. Consequently, if vaccination does not prevent transmission, then the personal decision does not affect others. Therefore, there is a good reason to allow exemptions from the general rule.

Promoting public health and protecting against diseases are legitimate and constitutionally acknowledged purposes. Vaccination might be a tool for achieving these, but it must not become the purpose itself. If other tools are available, then the regulation should accept them in cases where they fit the individual's conscience better. Goldner Lang arrived at a similar conclusion from an EU law perspective. She argued that

EU vaccination certificates, where only the proof of vaccination would enable individuals to travel across the EU, are non-compliant with EU law, both at the time when there are insufficient vaccines and later on, when they become widely available. This is due to their discriminatory effect on certain categories of Union citizens and, possibly, even on certain EU nationalities during the time when they are scarce. By contrast, digital green passes have a wider scope and could avoid the shortcomings of vaccination certificates, but only once vaccines become widely available and only provided vaccination actually prevents or minimises the chances of transmission of the coronavirus. ${ }^{20}$

19 | According to the Bible, at the end of human history, no one will be able to buy or sell unless they have the mark of the Beast (Rev 13:17.). Christians may find it suspicious when economic activity is linked to a certain mark.

20 | Goldner Lang, 2021. 
How can this be converted into constitutional law? To maintain public health, there is a rationale for knowing who is and who is not infected with the virus. Put simply, one may categorise the population into 'sick' and 'healthy' groups. Let us accept the medical standpoint that those who are vaccinated or have previously been infected with the virus have immunity (i.e. they are 'healthy'). However, negative PCR tests or antigen tests show that the bearer does not belong to the 'sick' group, which logically means that they are 'healthy'. Still, the regulation requires the verification of 'healthy' status; being 'not sick' is not enough. I find it a constitutional deficit that vaccination IDs cannot be replaced by other tools with the same purpose.

\section{Can COVID-19 vaccination be mandatory?}

Mandatory vaccinations always restrict fundamental rights: They limit privacy rights and medical self-determination. Therefore, mandatory vaccinations can be constitutional only if they meet the criteria required for such restriction: The restriction must serve a legitimate purpose, and it must be necessary and proportionate to the aim. Promoting public health and reducing the effects of COVID-19 have been constitutionally acknowledged. The question of whether vaccination is necessary is an entirely medical issue. Constitutional law must rely on medical views and should accept that vaccination is necessary for immunity. Mandatory vaccination is proportionate if the regulation grants exemptions. The extent to which the law should consider medical, religious, or philosophical reasons as exemptions is a further matter of debate. Consequently, I find that there is no constitutional obstacle to mandating COVID-19 vaccination.

What the social effects of compulsory vaccination might be is a different issue. In Israel, which considered mandatory vaccination, the mere suggestion of a law banning unvaccinated health care and education sector employers from entering the workplace resulted in increased distrust among individuals who were already concerned about infringements on citizens' rights. ${ }^{21}$

Opel et al. examined whether COVID-19 vaccination should be mandatory for children and established the following criteria:

I Vaccine-related: The vaccine is safe and has an acceptable level of adverse effects; the vaccine is effective and increases safety in the school environment.

| Disease-related: The vaccine prevents diseases with significant morbidity and/or mortality and reduces the risk of transmission;

I Implementation-related: The vaccine is acceptable to the medical community, the administrative burdens are reasonable, and the burden of adherence is reasonable for the parent/caregiver. ${ }^{22}$

However, COVID-19 vaccination is currently not mandatory. This fact does not imply that there are no constitutional frameworks for vaccination. Under the current regulation, the question is not whether the law can mandate COVID-19 vaccination (such a question was not put officially) but, rather, whether the law can require vaccination as a condition 
of entry to particular events. For example, just because vaccination might be required for concerts and cinemas, it does not mean that it can also be required for fishing and playing tennis. Constitutional evaluations must be implemented individually in each case.

\section{Conclusion}

During a pandemic, it is incredibly difficult to estimate danger and evaluate our options correctly. The experience of the past 18 months shows that countries are prone to over- or underestimating the danger, which is perfectly understandable, as a pandemic had not occurred for generations. Defeating the coronavirus and reducing its impact are important objectives for states.

In the second half of 2020, the possibility of having access to vaccination gave new hope to societies; however, the general optimism was tempered by some scepticism and hesitancy. The reason for hesitancy was often freedom of conscience; either the vaccination itself or the manner of its promotion conflicted with psychological or religious considerations. This study examined how law and society should reflect on conscience-based vaccine hesitancy.

I conclude that COVID-19 vaccination can be made compulsory constitutionally under certain conditions. The regulations should meet a comparative test of burdens. The vaccine should be medically satisfactory and efficient in reducing the effects of the virus and minimising person-to-person transmission. This latter criterion is crucial: If vaccination does not reduce transmission, COVID-19 is a merely individual risk and not a social issue. The law should also grant possibilities for alternative behaviour that results in the same outcome, which is the verification of infection-free status. Finally, the regulation must provide an opportunity for exemptions in cases where the obligation to vaccinate would be disproportionate.

Vaccination is semi-mandatory in Hungary; there is no formal obligation to get vaccinated, but several areas of social life are linked to a vaccination ID. The list is changing. It was an extremely long list in early 2021; it was shortened in the summer, but it is uncertain how it will change in the autumn. Nevertheless, vaccine equity is much more important than vaccine passports. ${ }^{23}$ As Harrison and Wu point out

once this epidemic has fallen into historical memory, the development of the vaccine for COVID-19 should not be the indicator of a successful response, nor should it indicate the achievement of an improved health system. Vaccine confidence may be a better indicator. ${ }^{24}$

Vaccine confidence plays a significant role in convincing people to receive the vaccination. Political marketing and vaccination mandates do not convince people; they may even induce scepticism. Honest debates and social discussion are required. Society would be better served if people had honest discussions on the advantages and disadvantages of vaccination, accepting each other's standpoints, respecting different views, and the individual conscience. 


\section{Bibliography}

Dávid, L. (2011) ‘A Legfelsőbb Bíróság döntése az életkorhoz kötött kötelező védőoltások beadatásának megtagadásáról' ['The Supreme Court Decision on Refusing Mandatory Child Vaccination'] Jogesetek Magyarázata 2011/3.

Domingo, R. (2015) 'Restoring Freedom of Conscience', Journal of Law and Religion, 30(2), pp176-193 doi:10.1017/jlr.2015.5

Farber, A. D. (2020) 'The Long Shadow of Jacobson v. Massachusetts: Epidemics, Fundamental Rights, and the Courts', San Diego Law Review, 57 (pp833-864) .

Goldner Lang, I. (2021) ‘Vaccination for Vacation: Should the EU Have a “Digital Green Pass", "Vaccination Certificate" or Better Nothing?' Verfassungsblog. Available at: https://verfassungsblog.de/vaccination-for-vacation/ (Accessed: 5 December 2021) doi:10.17176/20210316-154013-0

Gostin, O. L., Salmon, A. D., Larson, J. H. (2021) ‘Mandating Covid-19 Vaccines', JAMA. 2021;325(6):532-533. doi:10.1001/2020.26553

Harrison, E. A., Wu, J. W. (2020) ‘Vaccine Confidence in the Time of Covid-19', European Journal of Epidemiology, 35, pp. 325-330. doi:10.1007/s10654-020-00634-3

Killmond, M. (2017) 'Why Is Vaccination Different? A Comparative Analysis of Religious Exemptions', Columbia Law Review, 117(4), pp. 913-952.

Kuminetz, G. (2009) 'A lelkiismeret mivolta és rendeltetése katolikus szemmel' ['Conscience and Its Purpose from a Catholic Perspective'], Iustum Aequum Salutare, 2009/3, pp. 19-56.

Opel, D.J., Diekema, D.S., Friedman Ross, L. (2020) 'Should We Mandate Covid-19 Vaccine for Children?’ JAMA, 175(2), pp.125-126. doi:10.1001/jamapediatrics.2020.319.

Pelčić, G., Karačić, S., Mikirtichan, G. L., Kubar, I.O., Leavitt, F. J., Cheng-tek Tai, M., Morishita, N., Vuletić, S., Tomašević, L. (2016) 'Religious Exception for Vaccination or Religious Excuses for Avoiding Vaccination', Croatian Medical Journal, 5, pp. 516-521.

Szendrői, A. (2020) ‘Egy szúrás az egész?! Az életkorhoz kötött kötelező védőoltásokat övező személyiségi jogi kollíziók' ['Just One Twitch?! Privacy Issues concerning AgeBased Vaccination'], Miskolci Jogi Szemle, 2, pp. 186-199.

Tanner, R., Flood, C. M. (2021) 'Vaccine Passports Done Equitably', JAMA, 2(4), . doi:10.1001/jamahealthforum.2021.0972

Torfs, R. (2016) 'The Presence of the Cross in Public Spaces from the Perspective of the European Court of Human Rights' in Stanisz, P., Zawiślak, M., Ordon, M. (eds.) Presence of the Cross in Public Spaces. Cambridge: Cambridge Scholars Publishing.

Vaz, O. M., Ellingson, M. K., Weiss, P., Jenness, S. M., Bardají, A., Bednarczyk, R. A., Omer, S. B. (2020) 'Mandatory Vaccination in Europe', Pediatrics, 145(2), e20190620. https:// doi.org/10.1542/peds.2019-0620 
Wilf-Miron, R., Myers, V., Saban, M. (2021) 'Incentivizng Vaccination Uptake: The “Green Pas" Proposal in Israel', JAMA, 325(15), pp. 1503-1504. https://doi.org/10.1001/ jama2021.4300

\section{Case law}

\section{Hungary}

Supreme Court of Hungary

Bfv.II.25/2009/5.

BH2020.147.

Constitutional Court

39/2007 (VI. 20.) CC decision

3049/2020 (III. 2.) CC decision

\section{US}

Jacobson v. Massachusetts, 197 U.S. 11 (1905) 